\title{
O PAINEL VISUAL COMO FERRAMENTA PARA DESENVOLVIMENTO DE PRODUTOS DE MODA
}

\author{
THE VISUAL BOARDS AS A TOOL FOR FASHION PRODUCT DEVELOPMENT \\ KORNER, Edson; Mestrando; Univille \\ Edson.korner@pr.senai.br
}

\section{Resumo}

Este artigo aborda a utilização de painéis semânticos como técnica para o processo de visualização conceitual no desenvolvimento do projeto de produtos de moda. Assim, discutese a importância dos painéis semânticos como um exercício de interpretação visual no processo de criação. Esta ferramenta estabelece vínculos entre os conceitos abstratos e a forma do projeto. Portanto, interessa a esse artigo investigar como os painéis de inspiração que impulsionam o desenvolvimento de uma coleção de moda são importantes para o desenvolvimento do projeto.

Palavras Chave: Design de Moda; inspiração; painel semântico.

\begin{abstract}
This paper addresses the use of semantic boards as a technique for the process of conceptual visualization within the development of fashion products. Thus, we discuss the importance of semantic boards as an exercise of visual interpretation during the creation process. This tool is used by the fashion designer to help establishing links between abstract concepts and the shape of the final design within the projectual methodology. The aim of this article is to investigate the importance of these inspiration boards for the development of the project, once they drive the development of a fashion collection.
\end{abstract}

Keywords: fashion design, inspiration, semantic panel. 


\section{GAMPI
plural ${ }^{15}$}

\section{Introdução}

$\mathrm{Na}$ construção de um projeto de coleção de moda o designer tem como desafio transformar os conceitos abstratos em produtos concretos. Nas primeiras etapas de um projeto obtêm-se muitas informações visuais, por meio de imagens. Para o campo do design, a imagem é um veículo. $\mathrm{O}$ designer, necessita da imagem para expressar suas ideias. Embora, como refere Bonsiepe (2011, p.179), o design tenha levado tempo para progredir no campo reflexivo, durante esse processo de adequação e evolução, o designer tem na era da informação, o desafio de utilizar corretamente a informação intrínseca e como consequência, facilitar a absorção dessa informação. A imagem deve ser tratada pelo designer como informação, para que a partir dela sejam criadas ideias inovadoras.

Segundo Farias (2014) o modo de criação dos produtos é denominado projeto, considerando a união do conhecimento que caracteriza as metodologias de desenvolvimento de projeto de produto sendo assim a aparência do produto se dá a partir de um processo lógico constituído de etapas.

O processo de criação é feito em etapas com registros do processo de criação e ao criar uma coleção transmitimos conceitos. Designers projetam objetos para pessoas através do ensino projetual por meio de painéis de inspiração e semânticos que se organizam as referências coletadas visando organizar as ideias. No processo criativo de produtos do vestuário de moda utiliza-se a representação gráfica para configurar visualmente o que está sendo imaginado.

Discorreremos sobre os conceitos de painéis de inspiração e seus desdobramentos dentro do processo de desenvolvimento de coleção de moda. Para isso, o levantamento bibliográfico e dados coletados na forma de painéis semânticos, durante as práticas da disciplina de projeto de moda, complementam a abordagem desse artigo acerca das palavras chave do tema, despertando assim as discussões sobre imagem, design de moda e painel semântico como ferramenta visual para o processo de criação do designer de moda. A partir dessas abordagens, o objetivo desse artigo é que o designer compreenda por meio das ferramentas citadas, a competência de projetar pelo olhar.

\section{Imagem e Design de Moda}

Para Pereira (2010) os indivíduos estão imersos num mundo de imagens de mídia, fotografias, desenhos e elas podem ser dinâmicas ou fixas, materiais ou visuais todas servem como direcionamento. Essas imagens facilitam o entendimento e qualificam o indivíduo socioculturalmente. O homem está cercado pelas imagens que deveriam servir de guia de orientação no momento que são orientados por elas.

A imagem está interligada a moda e ao tratar da concepção de moda, o designer confronta-se com variados e velozes estímulos que aguçam sua capacidade criativa. Isso se dá devido a moda ser vista como uma manifestação cultural, tornado-se fonte de estudos para entender seu mecanismo. Na busca do entendimento simbólico, e das práticas que definem a moda, a imagem é interlocutora em todas as etapas, seja para o primeiro insight, quanto para a representação final do seu resultado. Tem-se no design, o meio para corporificar uma ideia, 


\section{GAMPI plural 15}

com ajuda dos meios correspondentes, permitindo a sua transmissão aos outros (LOBACH, 2001, p.6).

No design de moda, através do projeto de coleção de moda, o designer corporifica e transmite seus conceitos abstratos em produtos concretos. Imagens são utilizadas em todas as etapas do projeto e contem em si, um conjunto de informações abstratas que por sua vez, ao que se espera, irão gerar produtos inovadores. $\mathrm{O}$ início de um novo projeto desencadeia novas ideias e uma ferramenta muito usada para capturar ideias e conceitos se dá por meio da captura de imagens que por sua vez conduzem a inspiração. Nos projetos de moda os designers trabalham com várias ações criativas no processo de desenvolvimento do produto. As imagens despertam o processo criativo nas suas diferentes fases projetuais, estimulando a produção de ideias. Uma das principais fases consiste em apurar a criatividade para produção de ideias. Para Coelho (2008) o designer materializa ideias, valores e conceitos, configurando-os através de objetos. E são as escolhas desses elementos que constituem a construção desses objetos. Sendo assim o produto de moda se torna emissor dessa produção de ideias que são produzidas através de composições visuais e por sua vez são interpretadas para o vestuário. Nesse sentido, Sanches afirma que "A coleta e análise imagética é algo muito explorado no desenvolvimento de vestuário, pois se tem uma visão geral das correntes estéticas que traduzem os comportamentos sociais" (SANCHES, 2007).

Para exemplificar como a imagem pode traduzir um conceito ou um produto expõe-se a seguir alguns paineis :

Figura 1 - Exemplo de painel de imagem 1

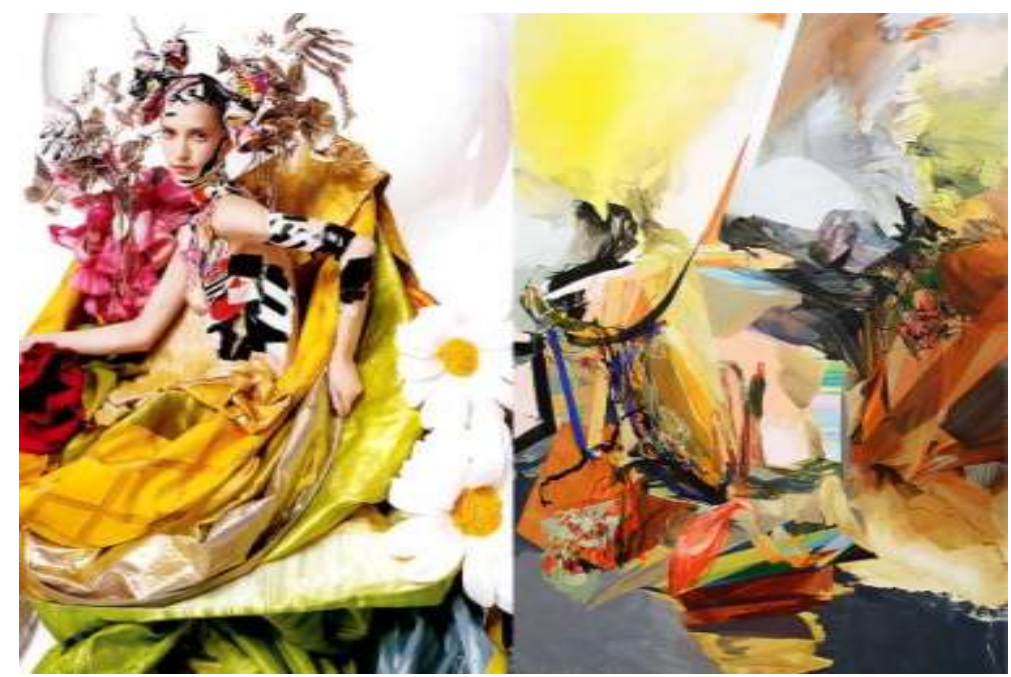

Fonte: http://whereiseefashion.tumblr.com/tagged/fashion (2015) 


\section{plural $^{{ }^{45}}$}

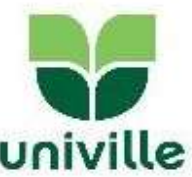

Figura 2 - Exemplo de painel de imagem 2

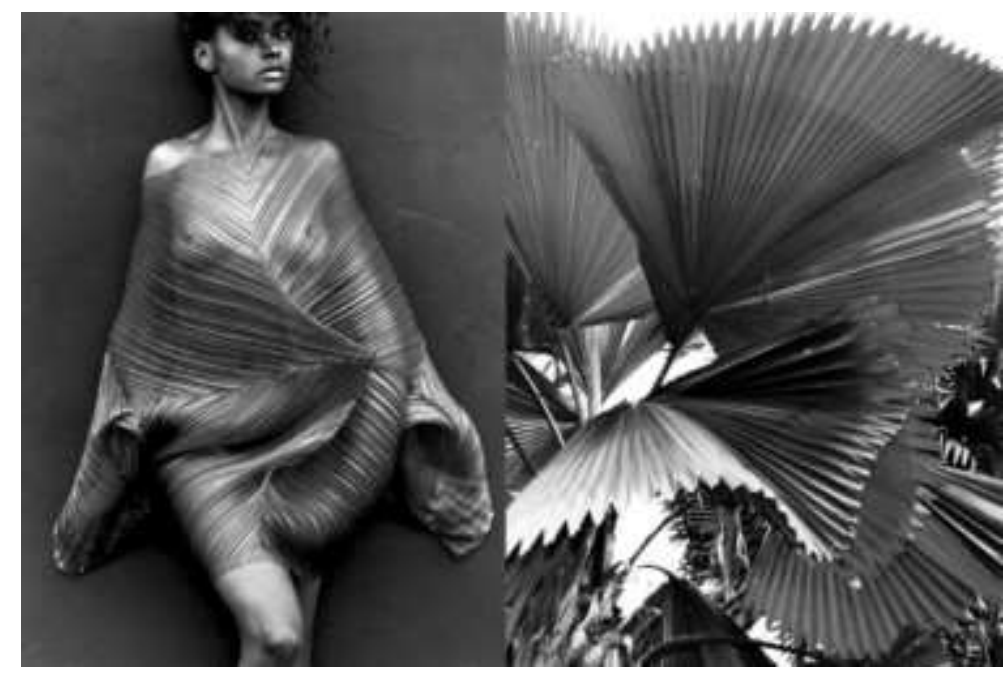

Fonte: http://whereiseefashion.tumblr.com/tagged/fashion (2015)

Figura 3 - Exemplo de painel de imagem 3

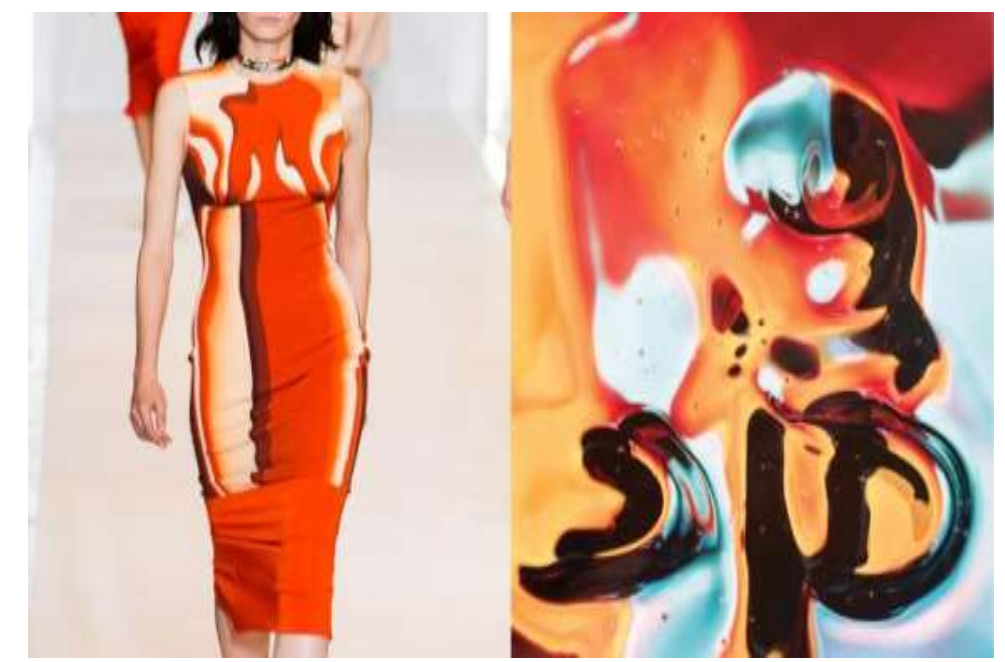

Fonte: http://whereiseefashion.tumblr.com/tagged/fashion (2015)

Bürdek (2006) valoriza as ferramentas de visualização como estratégia de síntese e comunicação, tendo em vista que muitas vezes a descrição verbal de metas, conceitos e soluções não são suficientes. Para Gomes (2001, p. 47), “criar é resultado de dois fatores bem distintos nos seres humanos: os sentidos perceptivos e a qualidade de conexões que o cérebro produz". Burdek (2005) afirma ainda que as imagens esclarecem dúvidas sobre o significado das palavras e usar painéis semânticos para o desenvolvimento de projetos torna-se uma ferramenta de criação e mediação. 
No desenvolvimento e configuração de produtos, é cada vez mais necessário se trabalhar com métodos de visualização. Particularmente no desenvolvimento do design, que é incorporado sob os aspectos globais, não são mais suficientes as descrições verbais de metas, conceitos e soluções. Os diferentes significados semânticos de termos ou conceitos podem ser muito diferentes entre os designers, técnicos e dirigentes de marketing (em uma equipe de desenvolvimento). No contexto nacional ou global, isto se torna ainda mais complexo e pode gerar equívocos de entendimento (Burdek, 2006, p. 265).

Munari (1998, p.34) diz que "projetar leva em conta todos os sentidos e, mesmo que à primeira vista o objeto possa agradar, se não agradar também aos outros sentidos será desprezado em favor de outro, que tenha a mesma utilidade, mas que, além de adequado na forma, é também agradável ao tato, tem peso correto, é feito em material adequado, etc".

O vestuário notoriamente é um portador de discursos simbólicos, transmitidos pela sintaxe de elementos visuais, torna-se imprescindível a sistematização de ferramentas que facilitem a concepção dessa carga comunicativa, especialmente para este tipo de artefato que é afetado rapidamente pelas transformações múltiplas do cenário contemporâneo, tornando o valor intangível o fator principal para a sua aquisição ou descarte (Sanches,2014,p.4)

Segundo Saches e Bolsok (2014) refinar as percepções visuais para um designer é de fundamental importância pois é onde acontecem a identificação das mensagens visuais do universo sociocultural que o permeia. Onde o desenvolvedor do projeto vai decodificar e transpor os elementos para criação e inovação de produtos de moda. Os autores ainda afirmam que:

\footnotetext{
Mediante este raciocínio, constatou-se que a síntese imagética é o recurso mais utilizado para organizar o raciocínio expressivo, mostrando-se eficaz também como forma de comunicação entre as pessoas envolvidas no projeto de moda. Desta forma, o conhecimento de metodologias e ferramentas para a sintaxe visual auxilia os profissionais e estudantes da área a compor códigos estilísticos que expressem mensagens não verbais coerentes às transformações do mercado de moda (Sanches e Bolsok, 2014, p.04).
}

Perazzo e Valença (2006) consideram ser imperativos o estudo e o entendimento dos diversos tratamentos dados às formas e à representação visual. $O$ processo criativo conseqüente decorre da relação entre o pensar, o representar, o pensar e o representar, sucessivamente, até se obter a melhor solução possível dentro das condições de tempo e recursos disponíveis. $\mathrm{O}$ uso de imagens e a representação gráfica auxiliam no desenvolvimento ou no aprimorando do projeto, servindo de suporte para a representação e a reflexão mental.

As imagens se formam a partir de um conjunto de signos que traduzem acontecimentos em cenas, pela reunião e coordenação de diferentes categorias signos icônicos análogos, signos plásticos (cores, formas, composição, texturas) e signos linguísticos (linguagem verbal). A relação entre significante, referente e significado produz os mais diversos sentidos. Tantos signos quanto imagens procedem à esfera do símbolo, permitindo serem interpretados a partir de poucos 


\section{plural $^{\text {GS }}$}

traços visuais, comuns às convenções que regem o contexto onde estão inseridos. (PEREIRA, 2010, p. 46).

Os paineis de inspiração são definidos como: "meios de comunicação visual ou multisensorial (textura, movimento, som) que podem ser utéis na construção do processo de comunicação e design" (McDonagh \& Denton, 2005, p.36).

\section{Ferramentas de inspiração para moda: painéis de imagens}

Para o design de moda, a coerente interpretação de uma imagem está relacionada as características e competências do designer em extrair da imagem informações que o conduzem a materias, cores, sensações e comportamentos do consumidor na atualidade.

Durante o processo de aprendizagem são utilizadas ferramentas visuais, que conduzem a confecção de painéis semânticos. As ferramentas auxiliam na sistematização do processo, tornando-se parte do pensamento do design.

Imagem e criação fazem parte de uma das dinâmicas do design. Devido a necessidade de organizar sistematicamente o pensamento sobre a dimensão estético-simbólica de um projeto, o designer deve ser capaz de realizar a síntese imagética. E que atue como ferramenta para a comunicação entre os profissionais que participam do processo de desenvolvimento de produtos, e também para a sua produção material, onde as referências de linguagem visual do designer são sintetizadas, servindo como fio condutor para a transmissão futura de sentimentos e emoções. Para Baxter (1996) os produtos devem ser projetados para transmitir certos sentimentos e emoções, e o uso de painéis de imagens visuais, painel de estilo de vida, de expressão do produto e de tema visual, são propícios para isso, e citando Gomes (2001) que considera as representações esquemáticas que facilitam a visão panorâmica e a reflexão sobre o processo, ao estimular cada sujeito a coordenar seu domínio de ação sob o mesmo foco, assim os painéis de imagem visuais devem ser valorizados na atividade projetual.

O design e a indústria correspondem-se através de uma relação pautada em valores reais, ou seja, produtos reais, etapas de construção e viabilidade real, que gera um resultado para o consumidor. Para o design, a imagem é estratégia de síntese e comunicação, tendo em vista que muitas vezes a descrição verbal de metas, conceitos e soluções não são suficientes (Bürdek ,2006). A imagem estimula o designer a encontrar respostas que interpretem fenômenos mais efêmeros, como cor, textura, forma, imagem e status. A imagem posicionase para o designer como resposta para um diálogo interno, que inicia-se com sua sua investigação a respeito de um tema, e depois é transportada ao produto industrial .

O painel semântico é uma ferramenta visual que conduz a inspiração por meio de imagens. Sendo utilizado, para decodificar imagens, o painel semântico é uma importante ferramenta de inspiração para o desenvolvimento de coleção de moda. Constituído por imagens, a concepção desses painéis podem se dar por diferentes técnicas, que por sua vez recebem nomes, como Mood Charts ou Mood Board, que utilizam a técnica da colagem de imagens que reúne fotografias, imagens de revistas ou Internet, amostras de tecidos, desenhos, objetos, texturas e cores (Garner \& McDonagh, 2008). Ainda para Garner e MacDonagh é um painel de imagens baseado nos códigos de linguagem referentes ao usuário e para Bürdek (2006) é uma técnica de colagem ("charts") que auxilia o designer a adaptar ao universo do público alvo. 


\section{plural $^{\text {GA }}$}

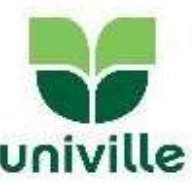

Utilizado também pelos designers para comunicar e partilhar uma visão com outros membros da sua equipe e clientes. Segundo McDonagh e Storer (2005) "Mood board é um método que pode potencializar a inspiração e comunicação durante um processo de design". Tanto para o ensino do design de moda, suas práticas pedagógicas, como para profissionais e indústria, dada a dinâmica acelerada na qual a criação e interpretação das imagens se insere, observar diferentes painéis de imagens, desenvolve a percepção do designer por meio do olhar. Conforme Pereira (2010) as imagens são interfaces que trazem sentidos a partir de experiências, expectativas e pré-conceitos de quem está no papel de observador. As imagens portanto são fontes enriquecedoras do design de moda, podendo estar representadas sob diferentes formatos durante as etapas projetuais. Para Sorger e Udale (2009, p.26) "painéis de inspiração, temáticos e conceituais são essencialmente uma destilação da pesquisa".

$\mathrm{Na}$ disciplina de projeto de moda, há o apoio constante das imagens coletadas para diferentes etapas. Assim, os painéis de imagem de acordo com cada etapa projetual, se apresentam da seguinte forma:

a) Painel de Público-alvo ou de Estilo de Vida: que relaciona-se ao perfil e estilo de vida do público alvo. Como explica Souza (2010) é a coleta de imagens que têm o objetivo de mostrar e expressar os valores pessoais e sociais dos consumidores ilustra o seu trabalho, cotidiano, hobby e outras situações e ocasiões que tenham a capacidade de traduzir a personalidade do usuário. Seivewwright (2009) complementa que painéis de estilo de vida são:

Imagens representando o estilo: Esse elemento está intimamente ligado ao mercado, pois as imagens que representam o estilo ajudam a apresentar suas criações, dentro de um contexto de estilo de vida. As imagens selecionadas podem produzir uma personalidade ideal para uma coleção. (SEIVEWRIGHT, 2009, p.97).

Pazmino (PAZMINO, 2015) afirma que usar as imagens para caracterizar um público alvo serve como uma ferramenta para o processo cognitivo par que se perceba de forma clara o público que irá trabalhar. Ainda segundo Pazmino (2015):

A partir das imagens do painel é possível identificar e conhecer aspectos como: cores, materiais, características formais ou tecnológicas que agradam ao públicoalvo. O designer de produto poderá desenvolver formas, cores, características de estilo que correspondam com o estilo de vida do público-alvo. ( PAZMINO, 2015, p.105).

b) Painel de Pesquisa de Tendências: refere-se a compilação de imagens de tendências de cada estação que regem o estilo no setor da moda. Esse painel indica materiais, gama de cores e tipos de modelagens. Treptow (2013) define o painel de tendências como um conjunto de informações que são agrupadas de uma forma visualmente agradável e com fácil identificação visual. E é através desse painel que o designer poderá visualizar quais elementos poderá usar em suas criações.

c) Painel de Tema ou Conceito Visual: refere-se a o conjunto de imagens que ajudam a inspirar e criar uma nova abordagem para o estilo através da observação e combinação de 


\section{GAMPI
plural 15}

formas. Para Baxter (1998) é a reunião de figuras de produtos que transpõem semelhante conceito, referência (tema) e sensação adotada para a criação do novo produto. O painel de tema " serve para mostrar à outra pessoa a origem e o caminho percorrido pela sua pesquisa" (SEIVEWRIGHT, 2009, p.95). Deve ser um guia para explicar as imagens mais significativas que irão servir se inspiração.

Pazmino (2015) define este painel como um auxílio e que pode ajudar na visualização do significado na geração de alternativas a criação do estilo do produto e definindo aspectos semânticos e simbólicos. Deve apresentar o significado a primeira vista que o produto irá passar.

Os paineis visuais acima ilustram como o uso da imagem pode direcionar o processo criativo, conduzindo o pensamento na associação de ideia, tornando-se então importante ferramenta para as práticas projetuais. No momento em que, conforme Farias (2014) no processo de construção de paineis visuais diversas materialidades são coladas, justapostas, superpostas ou fundidas e assim interpretam o pensamento.

\section{As práticas projetuais: PROJETAR PELO OLHAR}

O painel semântico, em suas diferentes técnicas e composições para a coleta de inspiração imagética, são os meios utilizados, para decodificar imagens, sendo abordado nesse artigo, quanto sua importância como ferramenta para o desenvolvimento de coleção de moda. Tanto para o ensino do design de moda, suas práticas pedagógicas, como para profissionais e indústria, discutir esse assunto é importante, dada a dinâmica acelerada na qual a criação e interpretação das imagens se insere.

Usam-se vários sentidos no processo de criação para interpretar imagens e cabe ao designer traduzir seus sentidos através do material pesquisado. Através do olhar comunicamos os valores estéticos e simbólicos que são percebidos pela visão. No processo metodológico precede a criação. A representação desses sentimentos através da ação manual ou gráfica é eficaz para o desenvolvimento de novos produtos.

O olhar do designer é caracterizado, principalmente, pela articulação que a disciplina estabelece com diferentes saberes. A forma de conduzir essa articulação é orientada pelos objetivos propostos, pelos métodos utilizados e pelo campo de atuação em que o objeto de estudo se insere. Ou seja, a construção desse olhar é diversificada tanto quanto é diversificado o corpo teórico com o qual o design se relaciona (FERREIRA e COUTO, 2012, p.12).

As imagens circulam na mente do criador e não podem ser capturadas pelo outro, portanto é um processo de organização imagética individual do designer, é o momento em que para Sanches os elementos visuais devem ser analisados, selecionados e interrelacionados, canalizando o direcionamento de aspectos semânticos necesssários" (SANCHES, 2007).

Para exemplificar o uso da ferramenta em um âmbito profissional e acadêmico expõe-se a seguir painéis da empresa Veine e Lafort e painéis de construção executados no curso de Design de Moda da Faculdade de Tecnologia Senai Curitiba pelo aluno e designer Diego Malicheski. 


\section{GAMPI
plural $^{45}$}

Assim o público alvo de uma coleção de moda é representado por imagens, como nos paineis do designer Diego Malicheski (Figura 4 e 5) . Em geral, as imagens também são descritas e interpretados por palavras, que relatam e justificam suas propriedades. Esse paineis tem a função de compreender a origem de seu público-alvo, seu comportamento de consumo e seu estilo de vida que são representados pelo seu comportamento. São informações que podem ajudar o designer a segmentar seu conteúdo de forma mais eficiente dentro do processo de construção de uma coleção de moda.

Figura 4 - Painel de público alvo para o curso de design de moda

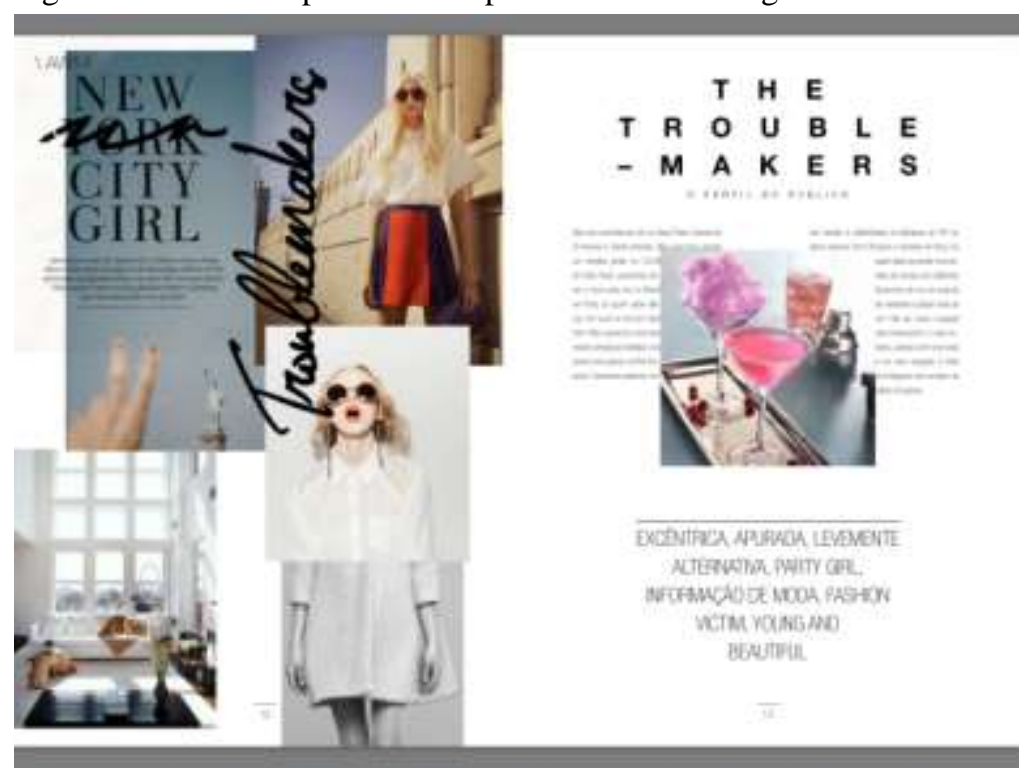

Fonte: Diego Malicheski (2014) ${ }^{1}$

\footnotetext{
${ }^{1}$ Projeto desenvolvido pelo aluno Diego Malicheski para a disciplina de Projeto de coleção I no curso Design de Moda da Faculdade de Tecnologia Senai Curitiba.
} 


\section{GAMPI plural 15 .}

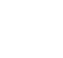

Figura 5 - painel de público alvo para o curso de design de moda

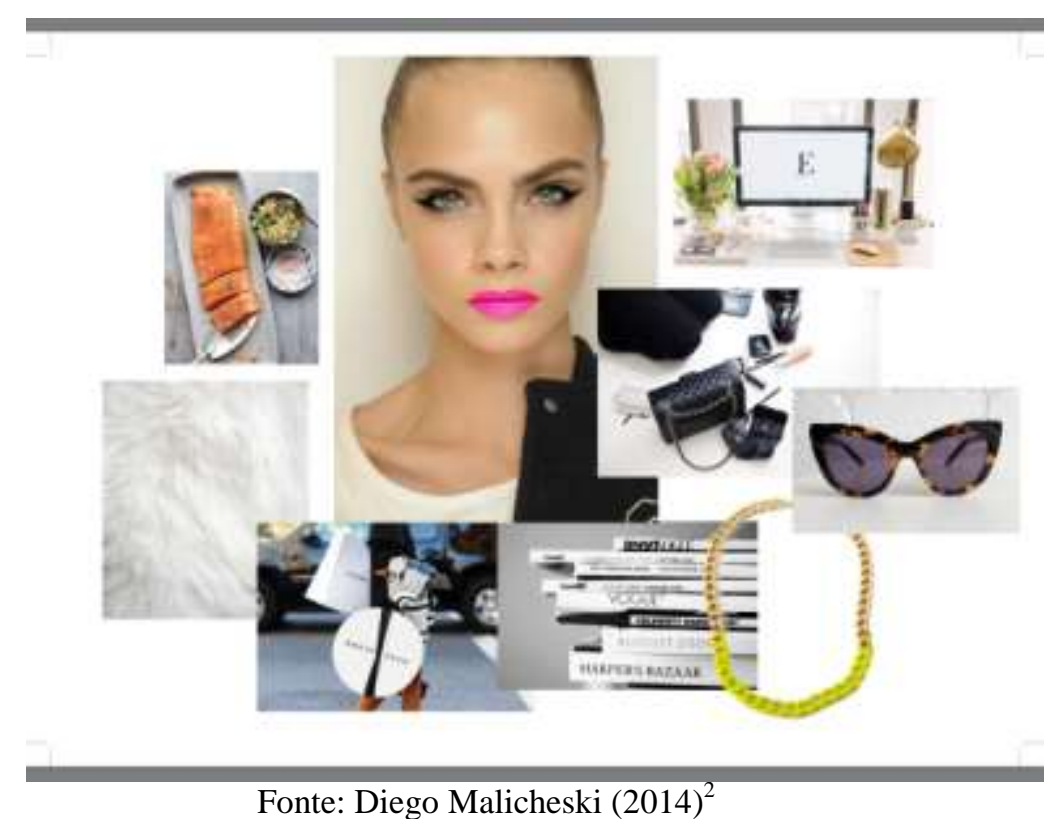

Ao criar um painel para seu consumidor, constrói-se uma clara identidade à qual pode recorrer ao selecionar tecidos, cores, formas e estampas. Esta descrição observada na figura 6 no painel visual do consumidor também pode informar sobre as escolhas de desenvolvimento das criações dos produtos. É um processo que facilita a lembrança constante da pessoa para a qual coleção está sendo criada.

\footnotetext{
${ }^{2}$ Projeto desenvolvido pelo aluno Diego Malicheski para a disciplina de Projeto de coleção II no curso Design de Moda da Faculdade de Tecnologia Senai Curitiba.
} 


\title{
GAMPI
plural ${ }^{15}$
}

Figura 6 - descrição público alvo para projeto do curso de design de moda

\begin{abstract}
Sofisticaçoo, imagem, beleza e moda soo caracteristices intrinsecos de uma Uptown Girl. Sâo mulheres jovens que costumam morar em regióes de alto padrấo em capitais da regióo Sul e Suldeste do Brasil, com seus pais ou em seus próprios apartamentos.

Quando crianço o Uptown Girl eco a moderninho do boirro, ogora ela é referéncia de estilo entre as pessoas qua a cercam. Sua personalidade e particular, mos ela sampre marca presenço por onde posso sendo discreto ou do tipo que falo mais alto. Elo é differente, e é early adopter dos looks que vocè pensa duas vezes antes de sair casa vestindo.

Frequenta shoppings, cafés, bisträs, nail lounges a eventos sociois em clubes. Uma Uptown Girl nóo costumo consumir bebidas alcóolicas enquanto está rodeada de pessoas desconhecidos, mas as vezes quebra esta regra quando se trota de pistes de dença e locais públicos demais. Livrarias e galerios de arte sáo para encontrar inspiraçōo e, ocasionalmente, adquirir uma obra assinado do autor/artista durante o coquetel da sessoo de autogratos. Os eventos de modo como fashionweeks e lançamentos de boutiques fambém preenchem sua agenda, mas jó deikoram de ser datas especiois. Talovisbo nóo é seu forte, mos quando elo esta ligada permanece no El ou VHl para momentos ecleticos. Revistas de modo como Harper's Bazoor, Elle, Vogua, W, o Nylon sáo recebidas periodicamente impressas e no iPod. A alimentaçóo da Uptown Girl é regulada, optondo por refeiçóes leves e saudarveis sempre que possivel. Ela frequenta estúdios de pilates semanalmente mesmo com uma rotina agitada na agencia/escritorio, pois sabe que manter a forma ef fudo no universo.

Ela é workaholic declarada, odora o que faz e está a caminho de ser um destoque na área, proenchendo posiçóes importantes pois tem atitude, conquistando seu próprio espaço de forma dinámica. Na maioria das vezes trabolha com publicidade de modo, umo dos suas grandes paixoes que interfere diretamente no seu dia-a-dia. A rotina de uma Uptown Girle disputada por compromissos cam o trabalho, vida sacial e ainda sua vida particular. E no celular que ela se organiza e mantém contato com as amigas/namorado, por isso é um dos itens que ela jomois sairo de coso sem. Como publiciória, ela nâo dispensa seu modo highlow urbano de se vestir, já que a profissáo náo exige nenhum tipo de uniforme au restriçáo quanto oo vestuário. Sev closet e bem eloborodo com peças selecionodas de fostfoshion lque ela é fá declarada) e de marcas que ama, e assim ela busca must-haves ideais que nem sempre fozem parte das tendéncios do momento, mas noo deixam de ser um objeto de desejo. O bom senso e bom gosto sáo carocteristicas herdadas de berço, o que permite ela viajar em diversos estilos sem perder sua personalidade, ou seja, na segunda-feira ela e romántica folk mas na terça-feira jo está minimal sport sem perder sua essência de Uptown Girl.
\end{abstract}

Fonte: Diego Malicheski $(2014)^{3}$

Os paineis de tendências apresentam através das imagens as necessidades e desejos dos consumidores para uma estação específica. Por meio desses paineis a equipe e o designer de moda pode explorar quais tecidos, estampas, formas e cartelas de cores serão usadas na estação. Fotos de passarela e editoriais de moda compõe essa representação. Os exemplos na figura 7 mostar o painel de tendência e como o designer oportunizou através do painel a visualização de cores e formas para coleção apresentada na figura 8 .

\footnotetext{
${ }^{3}$ Projeto desenvolvido pelo aluno Diego Malicheski para a disciplina de Projeto de coleção II no curso Design de Moda da Faculdade de Tecnologia Senai Curitiba.
} 


\section{GAMPI
plural $^{45}$}

Figura 7 - painel de tendências para o curso de design de moda

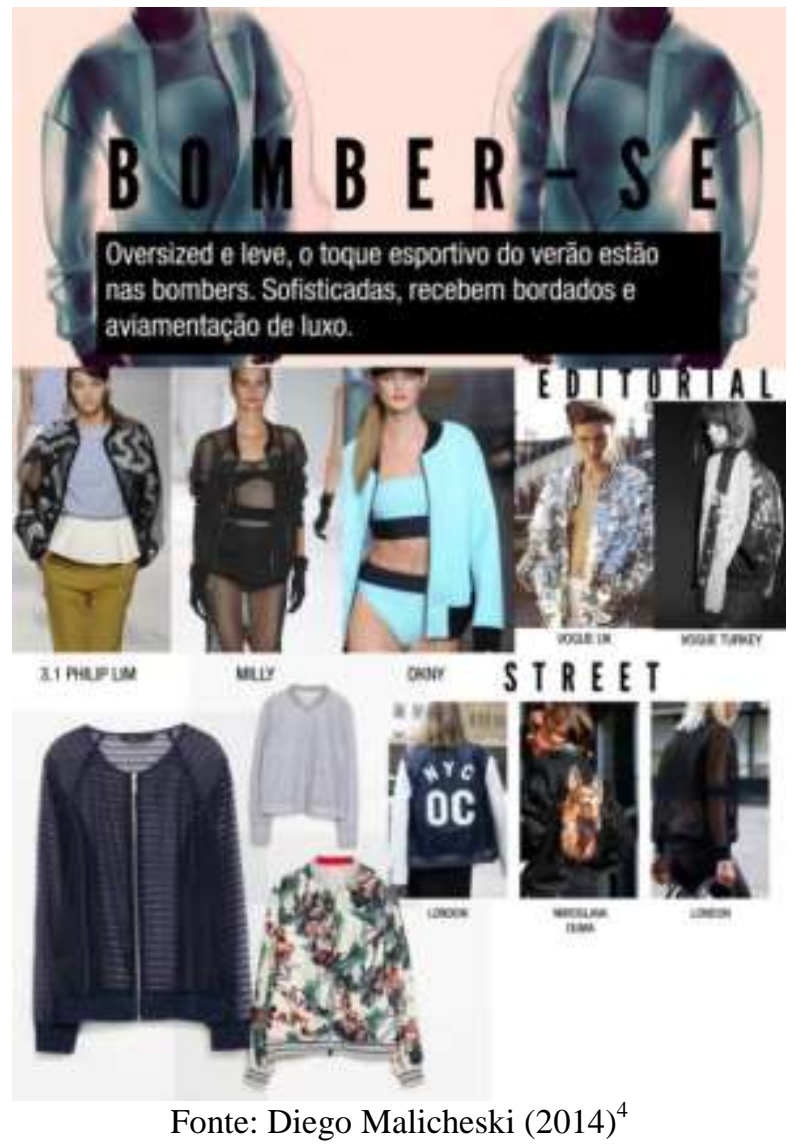
${ }^{4}$ Projeto desenvolvido pelo aluno Diego Malicheski para a disciplina de Projeto de coleção III no curso Design
de Moda da Faculdade de Tecnologia Senai Curitiba. 


\section{GAMPI plural ${ }^{45}$}

Figura 8 - criação de produto através do painel de tendências para o curso de design de moda

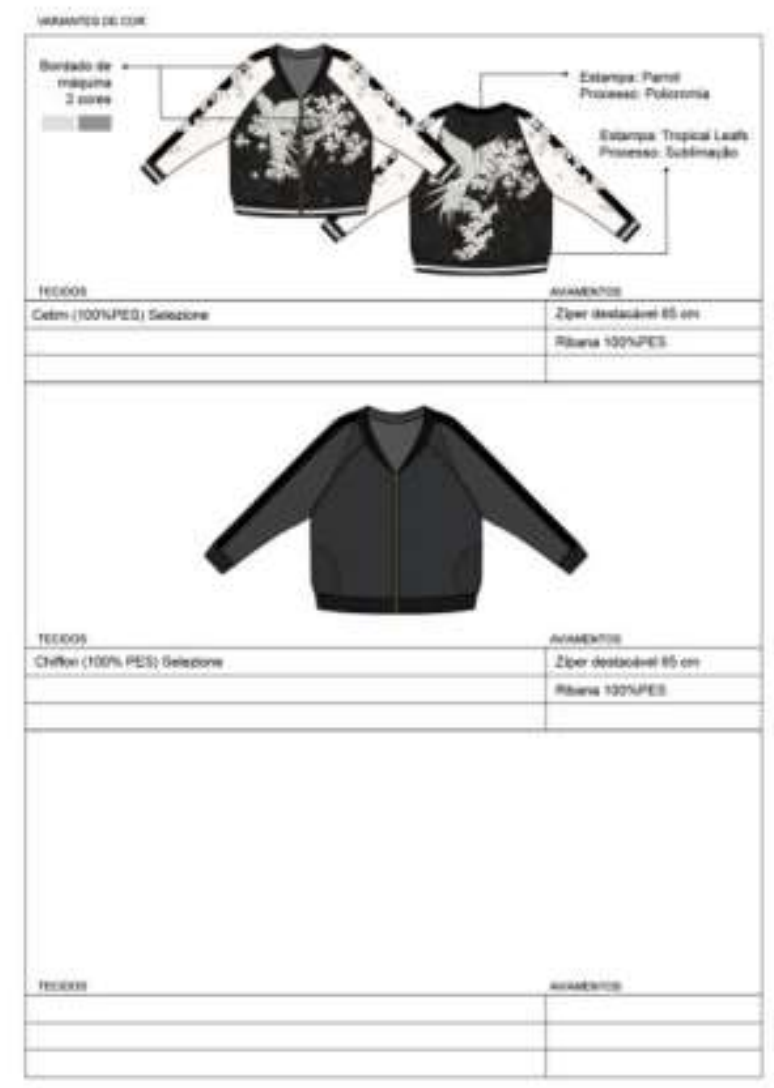

Fonte: Diego Malicheski (2014)

\footnotetext{
${ }^{5}$ Projeto desenvolvido pelo aluno Diego Malicheski para a disciplina de Projeto de coleção III no curso Design de Moda da Faculdade de Tecnologia Senai Curitiba.
} 


\section{plural $^{\text {GA }}$}

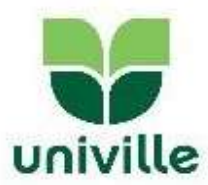

$\mathrm{Na}$ figura 9 o painel central do tema que apresenta imagens fortes representem a temática escolhida, e dessas imagens pode ser retirada a cartela de cores e palavras-chave para a coleção. Painel que retrata o espírito pretendido com o projeto. Deve ser construído por uma leitura visual de forma clara, objetiva e sutil. Tem o objetivo de colocar o designer em contato com a temática da coleção oportunizando novas idéias que serão transferidas para o processo de criação do produto de moda como mostra a figura 10.

Figura 9 - painel de tema de coleção para o curso de design de moda

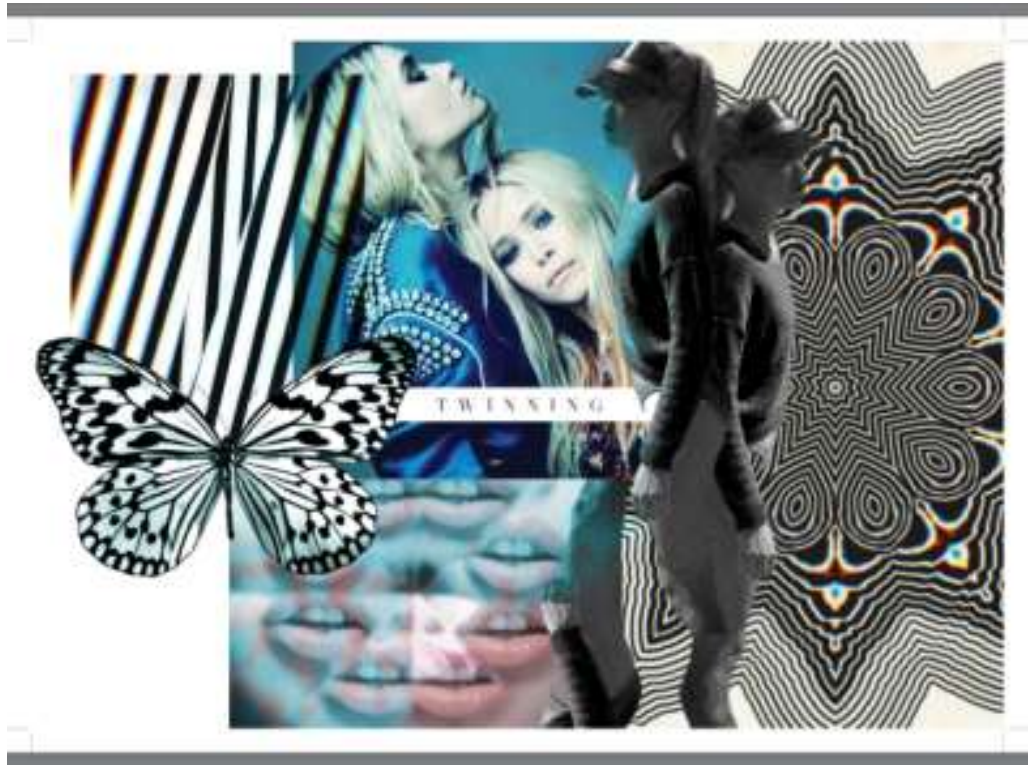

Fonte: Diego Malicheski (2014)

\footnotetext{
${ }^{6}$ Projeto desenvolvido pelo aluno Diego Malicheski para a disciplina de Projeto de coleção I no curso Design de Moda da Faculdade de Tecnologia Senai Curitiba.
} 


\section{GAMPI
plural ${ }^{45}$}

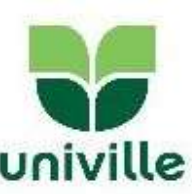

Figura 10 - desenvolvimento de coleção através do painel de tema de coleção para o curso de design de moda
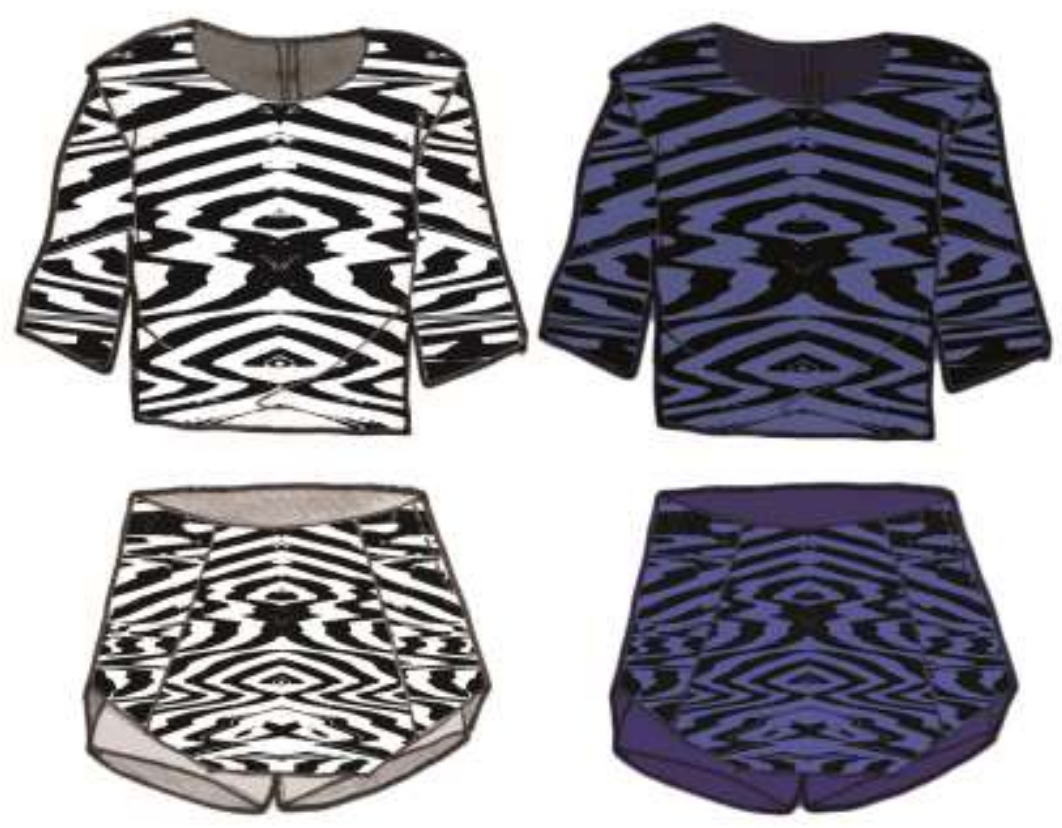

Fonte: Diego Malicheski $(2014)^{7}$

O Painel de tema é a representação do assunto ou pensamento de forma gráfica. Serve de guia para a criação da coleção e desenvolvimento de ideias. Transmite sensações e atmosfera, sentimentos e apoia no direcionamento de conceitos da coleção. As imagens são de assimilação mais rápida do que as palavras, portanto o painel será o instrumento usado para fazer com que todos os envolvidos no processo criativo, compreendam qual é a proposta da coleção. Na figura 11 o painel de tema de coleção da empresa Lafort mostra a sintonia com o universo do projeto com o tema Rússia apoiando para os conceitos para o projeto através de formas, cores e estampas conforme mostra a figura 12 .

\footnotetext{
${ }^{7}$ Projeto desenvolvido pelo aluno Diego Malicheski para a disciplina de Projeto de coleção I no curso Design de Moda da Faculdade de Tecnologia Senai Curitiba.
} 


\section{GAMPI plural ${ }^{45}$}

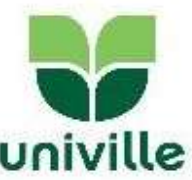

Figura 11 - painel de tema de coleção para empresa Lafort.

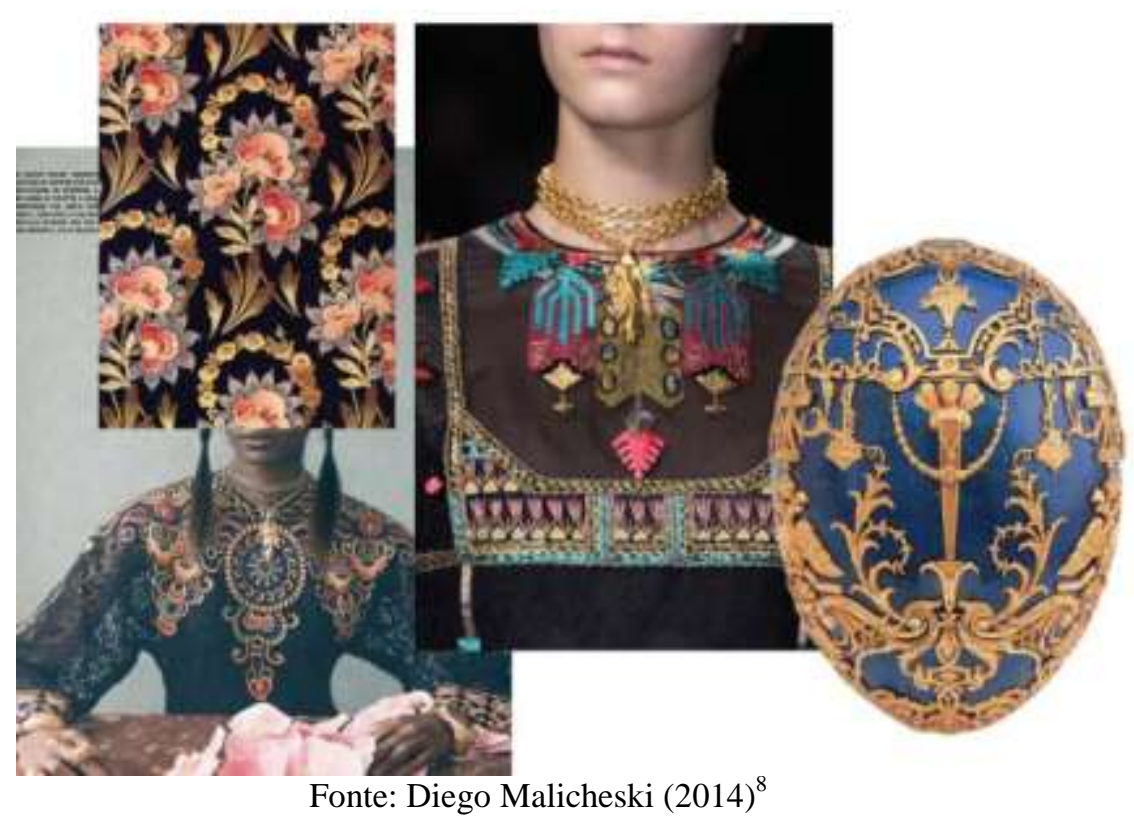

${ }^{8}$ Projeto desenvolvido pelo designer Diego Malicheski para a empresa Lafort. 


\section{GAMPI plural 45}

Figura 12 - Peça desenvolvida através de painel de tema de coleção para empresa Lafort.

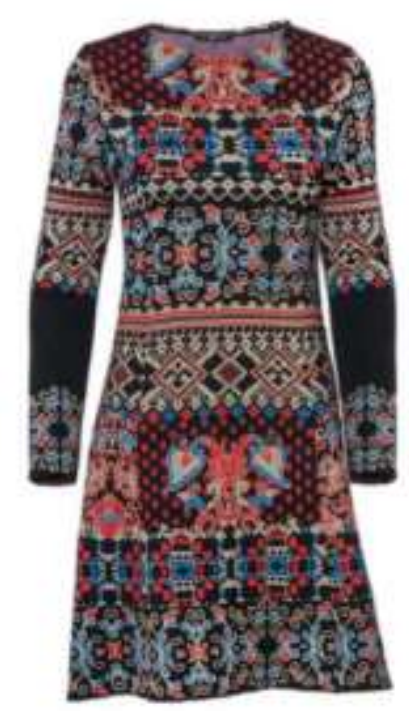

Fonte: Diego Malicheski (2014)

A coleta de imagens permite ao designer uma visão geral das tendências estéticas do momento. Por isso, a identificação e agrupamento dessas imagens em paineis torna o aproveitamento efetivo do painel como ferramenta projetual. É necessário que o designer desenvolva a capacidade de sintetizar a "essência" do produto por meio de uma imagem e, ainda, de extrair dessa imagem os elementos que caracterizam seu estilo. Mais que a capacidade criativa de um designer está na sua capacidade de análise onde pode expressar da melhor maneira seu processo criativo (Barbosa, 2009, p. 17).

\section{Considerações Finais:}

O uso de imagens para o design de moda, através do painel semântico, constitue uma importante ferramenta para o processo de criação de produtos de moda. $\mathrm{O}$ design se apresenta como um método aplicado para transformar conceitos em produtos. Sendo assim é importante para o designer não ser somente criativo, e sim possuir conhecimentos que lhe permitam representar visualmente suas ideias, comunicando-as de maneira eficiente.

Assim, para esse artigo, as imagens quando utilizadas em paineis, tornam-se fio condutor transformando as referências visuais, sentimentos e emoções em produtos.

Ao construir seu painel de imagens analisando elementos visuais, analisando-os, selecionando e direcionando-os o designer criar os aspectos semânticos necessários para

\footnotetext{
${ }^{9}$ Projeto desenvolvido pelo designer Diego Malicheski para a empresa Lafort.
} 


\section{GAMPI plural ${ }^{45}$}

desenvolver seu produto, e por fim, essa prática o conduz a criar pelo olhar. Importante competência a ser estimulada na aprendizagem nos dias de hoje.

Sendo o mood board uma ferramenta criativa não existe um modelo formalizado para sua construção. $\mathrm{O}$ designer pode separar as referências de imagens com relação aos aspectos a serem planejados como cores, ambientes, formas etc... E outro sem uma ordem definida servindo apenas de referência para o processo criativo. A importância da construção dos painéis está no seu resultado final e se transforma num meio de comunicação que coloca as imagens em sintonia com o objetivo do projeto de maneira clara e objetiva. A consulta dos painéis durante o processo criativo ajuda a manter o direcionamento das idéias e também com a comunicação da equipe de criação.

\section{Referências}

BAXTER, M. Projeto de produto: guia prático para o design de novos produtos. $2^{\mathrm{a}}$ ed. São Paulo: Edgard Blücher, 1998.

BOLSOK, F. C. ; SANCHES-MONTEMEZZO, M. C. F. . LEVANTAMENTO DE TÉCNICAS E MÉTODOS PARA A SINTAXE VISUAL EM PROJETOS DE DESIGN

DE MODA. In: $10^{\circ}$ Coloquio de Moda/ $7^{\text {a }}$ edição internacional, 2014, Caxias do Sul. Anais do $10^{\circ}$ Coloquio de Moda. Caxias do Sul: Universidade de Caxias do Sul e ABEPEM, 2014. v. 1. p. 1-4.

BONSIEPE, Gui. Design, cultura e sociedade. São Paulo: Blucher, 2011.

BURDEK, Bernhard E. História, teoria e prática do design de produtos. São Paulo: Edgard Blucher, 2006.

CAMPOS, Amanda; SOUSA, Richard. A representação visual da moda nos suportes gráficos. In: Cultura Visual, n. 18, dezembro/2012, Salvador: EDUFBA, p. 41-59.

FERRARA, Lucrécia D’Aléssio. Leitura sem palavras. 4. ed. São Paulo: Editora Ática, 2004. (Coleção Princípios).

COELHO, Luiz Antonio L. (org.) Conceitos-chave em design. Rio de Janeiro: Edtora PUCRio. Novas Idéias, 2008.

FARIAS, M. J. O. . Dinâmicas Comunicacionais no Processo Criativo de Design de Produto: Característica e Construção da Linguagem a Partir dos Painéis Semânticos. In: $11^{\circ}$ Congresso Brasileiro de Pesquisa e Desenvolvimento em Design, 2014, Gramado. $11^{\circ}$ 


\section{GAMPI plural ${ }^{45}$}

Congresso Brasileiro de Pesquisa e Desenvolvimento em Design. São Paulo: Blucher Proceedings, 2014. v. 1. p. 3212-3225.

FERREIRA, P. C. ; COUTO, R. M. S. . Sob o olhar do Design: a construção de um ponto de vista. Estudos em Design (Online), v. 20, p. 1-14, $2012 .$.

Garner, S. \& McDonagh-Philip, D. Problem Interpretation and Resolution via Visual Stimuli: The Use of 'Mood Boards' in Design Education. In: The Journal of Art and Design Education, 20(1)pgs.57-64,2001.

GOMES, Luiz Vidal Negreiros. Criatividade: Projeto, Desenho, produto. Santa Maria: sCHDS, 2001.

LÖBACH, B.. Design industrial: bases para a configuração dos produtos industriais. São Paulo: Edgard Blücher, 2001. 206p.

McDonagh, D.; Hekkert, P.; Erp, J.V.; Gyi, D.. Design e emoção: a experiência das coisas quotidianas. Taylor \& Francis, 2004.

McDonagh D. \& Denton H. Exploring the degree to which individual students share a common perception of specific mood boards: observations relating to teaching, learning and team-based design. Design Studies, 2005.

PAZMINO, Ana Veronica. Como se cria: 40 métodos para o design de produtos. SãoPaulo: Blucher, 2015.

SANCHES-MONTEMEZZO, M. C. F. ; MARTINS, S.R.M. . PROJETANDO MENSAGENS VISUAIS: a contribuição das ferramentas de síntese imagética no design de moda. In: $11^{\circ}$ Congresso Brasileiro de Pesquisa e Desenvolvimento em Design, 2014, Gramado. Anais do $11^{\circ}$ P\&D Design. Gramado: UFRGS;Unisinos; Uniritter, 2014. v. 1. p. 110.

SANCHES, Maria Celeste de F. A síntese visual como ferramenta projetual para a concepção de produtos de moda. In: CONGRESSO INTERNACIONAL DE PESQUISA EM DESIGN (CIPED), 4., 2007, Rio de Janeiro. Anais... Rio de Janeiro: ANPED, 2007. 1 CDROM.

SEIVEWRIGHT, Simon. Fundamentos de design de moda: Pesquisa e Design. Porto Alegre: Bookman, 2009. 


\section{GAMPI \\ plura 45}

univille

SENNA, Carlos E. ; BIAVA, L. C. . O vídeo semântico como ferramenta projetual para o desenvolvimento de produtos industriais. Tríades em Revista, v. 1.2, p. 1-10, 2011.

SORGER, Richard; UDALE, Jenny. Fundamentos de design de moda. Porto Alegre: Bookman, 2009.

I see fashion everywhere and everything in fashion. Disponível em: $<$ http://whereiseefashion.tumblr.com/tagged/fashion> Acesso em (07 ago 2015).

Interpretação e resolução de problemas através de estímulos visuais: o uso de 'Mood Boards' em Design Educação - ResearchGate. Available from: [accessed Jul 26, 2015].

TREPTOW, Doris. Inventando moda: planejamento de coleção. $5^{\text {a }}$ edição. São Paulo: Edição da autora, 2013. 